\title{
The Grandmother Effect: Implications for Studies on Aging and Cognition
}

\author{
James G. Herndon \\ Yerkes National Primate Research Center, Emory University, Atlanta, Ga., USA
}

\section{Key Words}

Grandmother hypothesis - Evolution · Aging and

cognition $\cdot$ Non-human primates

\begin{abstract}
Background: Women experience more years of vigorous life after ovulation has ceased than do females of other primate species. Is this an epiphenomenon of the greater life expectancy humans have enjoyed in the past century or so, or is long post-menopausal survival the result of an evolutionary selection process? Recent research implies the latter: Long post-menopausal survival came about through natural selection. One prominent line of thought explaining this selection process is the grandmother hypothesis. Objective: To evaluate the implications of the hypothesis for nonhuman primate studies of aging and cognition. Method: The author presents a synopsis of the hypothesis, evaluates the uniqueness of the 'grandmother effect' to humans, and discusses its implications for non-human primate models of cognitive aging. Results: The hypothesis contends that, in past epochs, women who remained vigorous beyond their fertile years may have enhanced their reproductive success by providing care for their grandchildren. This care would have enabled their daughters to resume reproduction soon-
\end{abstract}

er, endowing them with greater lifetime fertility. Genes of grandmothers possessing such old-age vigor would be more likely to persist in subsequent generations. Is midlife menopause a uniquely human phenomenon, or does the chimpanzee, our closest primate relative, also display this trait? If so, we might expect a grandmother effect in this species as well. However, female chimpanzees continue to cycle until near the end of their maximum life span of about 60 years. Conclusion: Long survival beyond fertility and a long life expectancy are distinctive human adaptations. The robustness of ancestral human grandmothers necessarily included resistance to cognitive decline through preservation of functions present in many primates but also development of processes of social cognition unique to our species. Cognitive traits such as language and social cognitive functions may function in our species in particular as mechanisms to compensate for age-related decline. This has significant implications for research in which non-human primates are considered as models of human cognitive aging; it also means that some processes can be studied only in humans.

Copyright $\odot 2009$ S. Karger AG, Basel

\begin{tabular}{ll}
\hline KARGER & (c) 2009 S. Karger AG, Basel \\
0304-324X/10/0561-0073\$26.00/0 \\
$\begin{array}{l}\text { Fax +4161306 1234 } \\
\begin{array}{l}\text { E-Mail karger@karger.ch } \\
\text { www.karger.com }\end{array}\end{array}$ & $\begin{array}{l}\text { Accessible online at: } \\
\text { www.karger.com/ger }\end{array}$
\end{tabular}

James G. Herndon, PhD

Yerkes National Primate Research Center, Emory University

954 Gatewood Rd. NE, Atlanta, GA 30329 (USA)

Tel. +1 404727 7752, Fax +1 4047273278

E-Mail james.herndon@emory.edu 


\section{Introduction}

Women may enjoy many years of life after their childbearing careers have ended. One explanation as to how a long life span past fertility arose in our species is the grandmother hypothesis. This hypothesis holds that, in response to ecological changes at the Plio-Pleistocene boundary, there was reduced availability of food that human juveniles could handle themselves. In response to these factors the human female derived selective advantage for remaining robust as her fertility declined, enabling her to assist her daughters in provisioning their children [1]. The hypothesis proposes that life after menopause is not merely a result of mankind's success in postponing death through medical progress and changes in lifestyle, but rather that continued vigor after childbearing years is an evolved component of the human life cycle. This grandmother effect has several implications for aging. First, grandmothers' prolonged vigor and ability to assist their offspring after they themselves are no longer capable of reproducing required concomitant evolution of resistance to age-related declines in vitality, including cognitive and social as well as physical robustness. Second, non-human species that do not display these characteristics present limitations as direct models of human aging processes.

In this essay, the author presents salient points of the argument that the long post-fertile life span of the human female is a derived trait that evolved along with motherchild food sharing and a long period of juvenile dependency $[1,2]$. Next, a controversy as to whether our closest living relative, the chimpanzee, experiences a period of extended post-menopausal infertility comparable to that of women is summarized. Finally, implications of the grandmother effect for research on age-related changes in cognition are discussed.

\section{The Grandmother Hypothesis}

A key question in theories of aging is why the life histories of animal species vary in terms of the relative amount of time spent during development and reproduction, and how these patterns may relate to aging. One important factor appears to be environmental risk of mortality. Charnov [2] argues that environments with low mortality risk provide more time to invest in growth and development as well as longer life. A related view is that of the 'disposable soma', which holds that there is a tradeoff between investment in the soma and the invest- ment in reproduction, based upon risks in the environment [3]. In this context, long-lived primate species are examples of a relatively greater investment in soma.

These ideas help explain why primates are long-lived, but why does Homo sapiens have such a long life span, even among primates? One view as to how selection pressure could change life history was provided by the 'stopping early' or 'mother' hypothesis, proposed by Williams [4]. He argued that menopause was a benefit to a woman because a '... termination of increasingly hazardous pregnancies would enable her to devote her whole remaining energy to the care of her living children, and would remove childbirth mortality as a cause for failure to raise these children'.

In contrast to this stopping early hypothesis, the grandmother hypothesis considers ovarian aging and menopause to be a conserved human trait, rather than a derived one, present before the branching off of the human lineage. It considers the derived trait to be slower aging in other physiological systems, resulting in a longer life span. A number of reviews of this hypothesis and its implications have appeared; it is briefly outlined here as it was put forth by Hawkes [5-7], one of its principal architects.

The grandmother hypothesis posits that ancestral females benefitted by retaining their strength as their fertility declined, enabling them to assist their daughters in caring for their children. The benefit of her longer survival was an increase in her daughters' fertility. Hawkes [5] argues that this change came about because ecological shifts forced dependence on foods that weanlings could not handle effectively. This presented an opportunity for an older female whose own fertility was ending to increase her own fitness by provisioning her grandchildren. According to this model, grandmothering explains increased adult survival and a longer life span. This, in turn, favors a longer period of prepubertal development [8].

A wide range of evidence establishes the plausibility of this concept. One line of support stems from observations of both modern-day traditional societies and historical accounts of pre-industrial Western societies. Among the Hadza, for example, one dietary staple are deep-growing roots that children have difficulty harvesting. Post-menopausal women, however, are able to dig them up, thus contributing to improved nutrition of their grandchildren [9]. Hawkes [5] points out that harsher, drier environmental conditions that appeared in the PlioPleistocene transition may have thus provided a 'novel fitness opportunity' for older women. She posits that 
these older females may have exploited this opportunity by helping to feed their just-weaned grandchildren, thus allowing their daughters to reproduce sooner without compromising the welfare of those weanlings [9]. The food-sharing that is the basis of the grandmother hypothesis may have involved other foods besides tubers that were too difficult for a child to handle, such as small game, shellfish, nuts, or seeds, as long as these were available in sufficient quantity in a particular ecological setting [1]. In addition to Hawkes' observations on the Hadza, several other studies describe societies in which work by grandmothers contributes to the material support of their daughters' weanlings in both modern [10] and historical populations $[11,12]$, as reviewed in Sear and Mace [13].

Does grandmothering indeed increase ultimate fertility? This question was addressed by Lahdenperä et al. [14], who analyzed archival data on longevity and reproduction of pre-industrial populations of about 500 Finnish and 2,300 Canadian women. Their primary finding in both of these groups was that the longer women lived after their childbearing years (i.e., after 50 years), the greater was the number of their grandchildren (produced by both sons and daughters). The Finnish dataset showed, in addition, that those young women living near to their mother began reproducing earlier and had greater lifetime reproductive success than did the daughters of women who were deceased or resided in a different village. Thus, at least in these two societies, the longevity of grandmothers is associated with increased number of descendants, suggesting that post-menopausal longevity indeed confers a selection advantage.

\section{Do Women Have Uniquely Long Lives after Childbearing Has Ceased?}

If this trait indeed evolved in the rising hominins, then Homo sapiens should be the only living species to display it. In a recent review of the literature on menopause in non-human primates, Walker and Herndon [15] observed that age-dependent cessation of ovulation occurs in all primate species studied. Rhesus monkeys, for example, reach menopause around 25-30 years of age, which is well beyond their median survival of about 16 years and near the maximum life span of about 35 years [16]. Thus, it is not menopause, but a lengthy post-menopausal life span that is lacking in monkeys. But if one accepts the scenario of working grandmothers improving their daughters' fertility, the question remains whether meno- pause evolved as a way of stopping reproduction, or whether longevity past menopause was the adaptation. In this regard, the chimpanzee is of particular interest as the species biologically most closely related to humans. In captivity, the median life span of this species is about 26 years and the maximum about 60 years ${ }^{1}$ [18]. Thus, the question is whether the chimpanzee's life history follows a 'non-human primate' pattern, with fertility declining in synchrony with somatic aging, or whether it exhibits a 'humanized' pattern, with menopause and reproductive cessation earlier in life so that a long post-reproductive period ensues.

In the case of the chimpanzee, it has been difficult to distinguish between these two schedules because of the scarcity of lifelong observations of their reproductive status. But the data available show that they continue to ovulate until near death [19-21], suggesting that chimpanzees, like other simians, follow the non-human pattern. However, a later report concluded that menopause occurs near mid-life, as it does in women. This later study on 14 chimpanzees found that FSH rose above what the authors designated as a critical level between 36 and 40 years of age [22] and concluded that menopause in chimpanzees occurred between 35 and 40 years of age. Although this study did follow individuals longitudinally, the authors were unable to observe actual menstrual cycles, relying instead upon twice-yearly samples of gonadotrophic hormones. Menstrual bleeding was not regularly observed in the chimpanzee facility.

Since menstrual bleeding has been observed regularly in many chimpanzees at the colony of the Yerkes National Primate Research Center for several decades, we examined the records for evidence of cyclic menstrual bleeding to directly track cycles and to determine when menopause occurs. Data were available for 664 chimpanzeeyears of observation on 89 chimpanzees, from the ages of 6 to 59 years. Twenty of the chimpanzees were observed into their 40th year of life (an age rarely achieved in chimpanzees in the wild or even in captivity $[18,23])$, and all of these showed cycles demarcated by menstrual bleeding after the age of 39 years. Three of the chimpanzees were observed into their 50s; all 3 showed cycles of menstrual bleeding past that age. We observed apparent menopause (defined as cessation of cycles for a period of at least 12

\footnotetext{
1 The popular press has presented claims that Cheeta, the chimpanzee in the Tarzan movies, has reached the age of 76 years. However, a recent report by a journalist who was preparing a biography of this supposedly superannuated chimpanzee found that Cheeta was actually around 45 years of age in 2008 , and the anecdotes supporting his advanced age were apocryphal [17].
} 
months without any underlying deterioration in overall health [24]) in only 1 chimpanzee. This individual ceased to display menstrual bleeding at 53 years of age. She stopped monthly cycles of genital swelling (which is dependent upon cycles of ovarian hormones [25-30]) at 57 years of age and lived in relatively good health until her death at 59 years [31].

While our data on chimpanzees clearly demonstrate that menstrual cycles can continue well past the age of 40 years and even into the $50 \mathrm{~s}$, one might still question whether the observed cycles are reproductively viable. However, a study of six groups of chimpanzees living in the wild indicated that live births occur at maternal ages as late as 40 or 50 years [23]. Late-life deliveries also can occur in captivity, as in a recent case report of a chimpanzee documented to be 49 years of age who gave birth to a healthy infant in a zoo in Switzerland [32].

Given these data and our finding that menstrual cycles can persist into the 50s, it seems that the chimpanzee does not possess lengthy, human-like post-menopausal survival. It therefore appears that a long and vigorous life, extending many years past the end of fertility, is a distinctive human trait.

It may be tempting to think that this human trait is merely an artifact of the lengthening of median human life expectancy in the last centuries. Extensive data, however, indicate that menopause and a long post-cycling life span have not emerged recently. Vaupel et al. [33], for example, noted that in a Swedish farming population, the death rate for women below the age of 70 years remained at a low and nearly constant level of about 0.05 throughout the period from 1875 through 1950. A high probability of adult survival past menopause has also been described in other historical populations as well as in human foraging societies [as reviewed in 5]. There are ancient references to menopause as well [see 34]. This echoes the commonplace observation that, throughout history, at least some women have lived to an advanced old age, well beyond the termination of fertility.

\section{Is Old-Age Cognition Different in Humans?}

It appears, therefore, that the long human life span is an evolutionary adaptation of our species. This adaptation must have involved maintenance of physical robustness of aged individuals, as in the case of the tuber-digging Hadza grandmothers [9]. The brain also must have evolved improved resistance to decline. Finch and Sapolsky [35] propose that this may have included metabolic changes that protect against Alzheimer disease-like pathology. Their proposal also implies that the human line developed general resistance against failing cognitive abilities. In the absence of enhanced cognitive resilience, extended life span may have been impossible, as failing brain function would likely cause increased mortality from environmental hazards, whereas preserved memory and decision-making ability would clearly be instrumental to survival. Indeed, Allen et al. [36] have suggested that increased brain size and greater cognitive capacity supported the development of increased life span in humans. They relate this brain-driven increase to the phenomenon of 'cognitive reserve', which compensates for brain lesions and pathology through excess capacity [37]. While Allen et al. [36] suggest a causal link between increased cognitive ability and long life span, an alternative view is that larger brains evolved because of the increased demands of an intercorrelated group of traits that included later age at maturity, longer life span, and large and complex social groups. The importance of social complexity for brain size is emphasized by Dunbar [38] in his 'social brain' hypothesis.

If the grandmother hypothesis indeed explains our long life span, then human late-life robustness - and decline - must be considered distinctively human. This implies that many aspects of cognitive decline can be studied only in humans, not in an animal model. Behaviors involving language, such as word generation or verbal memory, are obvious examples. In addition, other characteristic human abilities and behaviors may have been elaborated through grandmothering. For example, Carstensen and Lockenhoff [39] argue that other behaviors of grandmothers (and grandfathers) besides assistance with provisioning of weaned but dependent children may also have led to longer survival. They think that 'older kin may have contributed to the survival of younger individuals by providing instrumental support, knowledge, social expertise, and conflict resolution' and that the genes of older individuals making these investments in younger individuals are more likely to survive in subsequent generations. Some of these behaviors and abilities, they propose, improve, rather than decline, with age.

The uniqueness of some aspects of human aging does not lessen the importance of studying aging (and cognitive decline) in non-human primates; in fact, it emphasizes the importance of identifying and understanding the physical and behavioral traits that make us unique. Many studies of cognitive aging, including our own, have focused on non-human primates. Most of this work has been conducted on the rhesus monkey, rather than the 
chimpanzee. This species, it has been argued, shares many features of cognitive function with humans. In fact, humans and rhesus monkeys both display age-related decline in many of the same cognitive tasks. Both species are characterized by great variability in the display of cognitive loss, with some individuals displaying only modest impairment, even at advanced ages [40, 41]. To the extent that the rhesus monkey is an apt model of human aging, it also can provide a window upon neural mechanisms of the aging process, since the anatomy and physiology of this species can be studied more readily than in humans.

In this context, the chimpanzee represents an appropriate contrast with both the human and the widely studied rhesus monkey. With an average adult brain weight of about $385 \mathrm{~g}$ [18], the chimpanzee has about four times as much brain mass as the rhesus monkey (at $90 \mathrm{~g}$ [42]) and one-fourth the mass of the human (at about 1,300 g [43]); hence, the chimpanzee occupies a unique position in the animal kingdom with respect to humans and other nonhuman primates. The phylogenetic importance of the comparison with humans is underscored by the fact that the chimpanzee's brain, body size, and maturational pattern are similar to those of australopithocenes, the genus ancestral to Homo [5].

The comparison of these three species can offer information of practical benefit. Although we know that the rhesus monkey exhibits many of the same cognitive deficits that befall humans, we know little about cognitive decline in the chimpanzee. Does the fourfold advantage in brain mass over the monkey provide the chimpanzee with particular resistance to cognitive decline? There have been very few studies on the cognitive capacity of aged chimpanzees, but the available data suggest that the chimpanzee may actually be resistant to decline in one classic test of age-related decline in frontal lobe function: the delayed-recognition task. In this task, a treat or (for humans) another object is hidden in one of two locations while the subject looks on. Later, after a variable delay, the two hiding places are presented again. Normally, aged human and monkey subjects have difficulty remembering the location of the reward, and this difficulty increases with increased delay. Further, the effect of increasing delay has a disproportionate impact on aged persons and monkeys [44]. In the only study using this paradigm in 19 chimpanzees (aged 7-41 years), however, there was an advantage for the younger subjects only at the very shortest delay. As delays increased to a point where older monkeys began to be impaired, the older chimpanzees actually performed as well as the young [45]. While this early

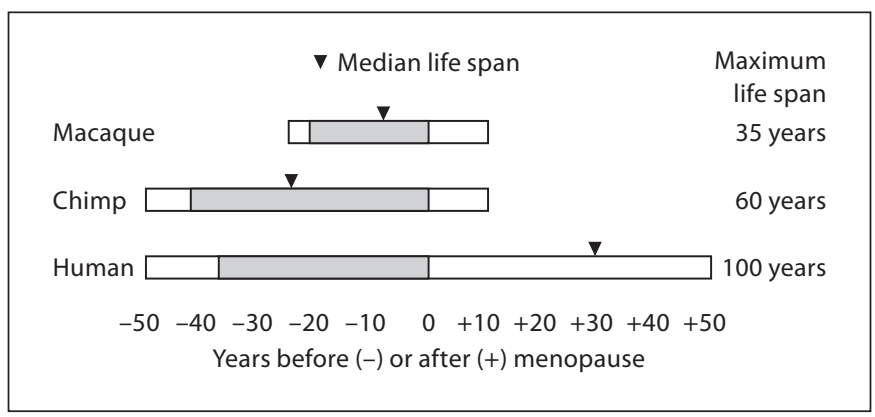

Fig. 1. Schematic diagram depicting approximate ages at puberty, menopause, and maximum life span of female macaques (Macaca spp.), chimpanzees (Pan troglodytes), and humans (Homo sapiens). Bars are aligned to the age at menopause; shading indicates the fertile time span between onset of puberty and menopause. Approximate ages used are based upon references [15, 16, 18, 48, 49]: puberty: $3.5,8,12.5$ years; median life span: $16,26,80$ years; menopause: $25,50,50$ years; life span: $35,60,100$ years. The age of 100 years was arbitrarily chosen for the human life span because survival to this age is very rare; only about 2 years of life expectancy remain in 20th century European and North American cohorts [50].

study was well carried out, it awaits replication to determine if chimpanzees are uniquely resistant to this agerelated change. Indeed, the finding that large brains are linearly correlated with longer life spans in primates [46] does suggest this possibility. But why do humans show an age-related deficit on this task? This question can only be answered by studies comparing chimpanzees and humans.

Figure 1 brings into sharp focus the contrast in life history among females of the three primate species discussed here. Rhesus monkeys live shorter lives than chimpanzees or women, with menopause occurring only in those few monkeys whose life spans approach the species' maximum. (Note that the median life expectancy in rhesus is only about 16 years.) Women and chimpanzees experience similar rates of ovarian aging [47] so that both species stop ovulating at about 50 years. However, most chimpanzees die before menopause, while most women survive well beyond. Physical strength, cognitive resilience, and social adaptability all play an important role in this peculiarly human phenotype. This human uniqueness increases the urgency of studying aging in other primates, an urgency heightened by the declining numbers and endangered status of chimpanzees and other apes. One reason for this is that the decline seen in other species may be accelerated at a rate proportionate to their relatively 'faster' life histories. Likewise, unique 
aspects of human brain morphology at molecular, cellular, and anatomical levels may provide clues to nervous system adaptations that have conferred a uniquely long life span upon humans. These same insights may help explain our susceptibility to such uniquely human scourges as Alzheimer, Huntington, and Parkinson diseases.

\section{Acknowledgements}

The author thanks Johannes Tigges, Agnès Lacreuse, Margarete Tigges, Kathleen Herndon, Lara Kristin Lentini, Lary Walker, Margaret Walker, Todd Preuss, James Rilling, Doris Jane Langford, Kristen Hawkes, and two anonymous reviewers for comments on the manuscript. Supported by National Institutes of Health grants P51RR000165 and P01AG026423.

\section{References}

1 O'Connell J, Hawkes K, Blurton Jones NG Grandmothering and the evolution of Homo erectus. J Hum Evol 1999;36:461-485.

2 Charnov EL: Life History Invariants: Some Explorations of Symmetry in Evolutionary Ecology. Oxford, Oxford University Press, 1993.

-3 Kirkwood TBL, Rose MR: Evolution of senescence: late survival sacrificed for reproduction. Philos Trans Biol Sci 1991;332:1524.

4 Williams GC: Pleiotropy, natural selection, and the evolution of senescence. Evolution 1957;11:398-411.

5 Hawkes K: Grandmothers and the evolution of human longevity. Am J Hum Biol 2003;15: 380-400.

6 Hawkes K: Life history and human evolution: a chronicle of ideas and findings; in Hawkes K, Paine RR (eds): The Evolution of Human Life History. Santa Fe, School of American Research Press, 2006, pp 45-94.

7 Hawkes K: Slow life histories and human evolution; in Hawkes K, Paine RR (eds): The Evolution of Human Life History. Santa Fe, School of American Research Press, 2006, pp 95-126.

8 Hawkes K, O'Connell JF, Blurton Jones NG: Human life histories: primate tradeoffs, grandmothering socioecology, and the fossil record; in Kappeler P, Pereira M (eds): Primate Life Histories and Socioecology. Chicago, University of Chicago Press, 2003, pp 204-227.

-9 Hawkes K, O’Connell JF, Blurton Jones NG: Hadza women's time allocation, offspring provisioning, and the evolution of long postmenopausal life spans. Curr Anthropol 1997; 38:551-577.

-10 Sear R, Mace R, McGregor IA: Maternal grandmothers improve nutritional status and survival of children in rural Gambia. Proc Biol Sci 2000;267:1641-1647.

-11 Jamison CS, Cornell LL, Jamison PL, Nakazato $\mathrm{H}$ : Are all grandmothers equal? A review and a preliminary test of the 'grandmother hypothesis' in Tokugawa, Japan. Am J Phys Anthropol 2002;119:67-76.

12 Voland E, Beise J: Opposite effects of maternal and paternal grandmothers on infant survival in historical Krummhörn. Behav Ecol Sociobiol 2002;52:435-443.
13 Sear R, Mace R: Who keeps children alive? A review of the effects of kin on child survival. Evol Hum Behav 2008;29:1-18.

14 Lahdenperä M, Lummaa V, Helle S, Tremblay M, Russell AF: Fitness benefits of prolonged post-reproductive lifespan in women. Nature 2004;428:178-181.

15 Walker ML, Herndon JG: Menopause in nonhuman primates? Biol Reprod 2008;79: 398-406.

16 Tigges J, Gordon TP, McClure HM, Hall EC, Peters A: Survival rate and life span of rhesus monkeys at the Yerkes Regional Primate Research Center. Am J Primatol 1988;15:263273.

17 Rosen RD: Lie of the Jungle: The Truth about Cheeta the Chimpanzee. Washington Post, Washington, DC, December 14, 2008.

18 Herndon JG, Tigges J, Anderson DC, Klumpp SA, McClure HM: Brain weight throughout the life span of the chimpanzee. J Comp Neurol 1999;409:567-572.

19 Bellino FL, Wise PM: Nonhuman primate models of menopause workshop. Biol Reprod 2003;68:10-18.

20 Graham CE: Reproductive function in aged female chimpanzees. Am J Phys Anthropol 1979;50:291-300.

21 Gould KG, Flint M, Graham CE: Chimpanzee reproductive senescence: a possible model for the evolution of menopause. Maturitas 1981:3:157-166.

22 Videan EN, Fritz J, Heward CB, Murphy J: The effects of aging on hormone and reproductive cycles in female chimpanzees (Pan troglodytes). Comp Med 2006;56:291-299.

23 Emery Thompson M, Jones JH, Pusey AE, Brewer-Marsden S, Goodall J, Marsden D, Matsuzawa T, Nishida T, Reynolds V, Sugiyama Y, Wrangham RW: Aging and fertility patterns in wild chimpanzees provide insights into the evolution of menopause. Curr Biol 2007; 17:2150-2156.

24 Burger HG: The endocrinology of the menopause. J Steroid Biochem Mol Biol 1999;69: 31-35.

25 Deschner T, Heistermann M, Hodges K, Boesch C: Female sexual swelling size, timing of ovulation, and male behavior in wild West African chimpanzees. Horm Behav 2004;46:204-215.
Graham CE, Collins DC, Robinson H, Preedy JR: Urinary levels of estrogens and pregnanediol and plasma levels of progesterone during the menstrual cycle of the chimpanzee; relationship to the sexual swelling. Endocrinology 1972;91:13-24.

27 Dahl J, Nadler RD, Collins DC: Monitoring the ovarian cycles of Pan troglodytes and $P$. paniscus: a comparative approach. Am J Primatol 1991;24:195-209.

28 Nadler RD, Graham CE, Gosselin R, Collins DC: Serum levels of gonadotropins and gonadal steroids, including testosterone, during the menstrual cycle of the chimpanzee (Pan troglodytes). Am J Primatol 1985;9:273284.

29 McArthur JW, Beitens IZ, Gorman A, Collins DC, Preedy JRK, Graham CE: The interrelationships between sex skin swelling and the urinary excretion of $\mathrm{LH}$, estrone, and pregnanediol by the cycling female chimpanzee. Am J Primatol 1981;1:265-270.

30 Emery Thompson M: Reproductive endocrinology of wild female chimpanzees (Pan troglodytes schweinfurthii): methodological considerations and the role of hormones in sex and conception. Am J Primatol 2005;67: 137-158.

31 Lacreuse A, Chennareddi L, Gould KG Hawkes K, Wijayawardana SR, Chen J, Easley KA, Herndon JG: Menstrual cycles continue into advanced old age in the common chimpanzee (Pan troglodytes). Biol Reprod 2008;79:407-412.

- 32 Puschmann W, Federer E: Ein neuer Fertilitätsnachweis bei einerhoch betagten Schimpansin und Anmerkungen zum Höchstalter von Pan troglodytes. Zool Gart 2008;77:182185.

-33 Vaupel JW, Carey JR, Christensen K, Johnson TE, Yashin AI, Holm NV, Iachine IA, Kannisto V, Khazaeli AA, Liedo P, Longo VD, Zeng Y, Manton KG, Curtsinger JW: Biodemographic trajectories of longevity. Science 1998;280:855-860.

34 Peccei JS: Menopause: adaptation or epiphenomenon? Evol Anthrop 2001;10:43-57.

35 Finch CE, Sapolsky RM: The evolution of Alzheimer disease, the reproductive schedule, and apoeE isoforms. Neurobiol Aging 1999;20:407-428. 
36 Allen JS, Bruss J, Damasio H: The aging brain: the cognitive reserve hypothesis and hominid evolution. Am J Hum Biol 2005; 17: 673-689.

37 Stern Y: What is cognitive reserve? Theory and research application of the reserve concept. J Int Neuropsychol Soc 2002;8:448460.

38 Dunbar R: The social brain hypothesis. Evol Anthrop 1998;6:179-190.

-39 Carstensen LL, Lockenhoff CE: Aging, emotion, and evolution: The bigger picture. Ann NY Acad Sci 2003;1000:152-179.

40 Herndon JG, Moss MB, Rosene DL, Killiany RJ: Patterns of cognitive decline in aged rhesus monkeys. Behav Brain Res 1997;87:2534.

41 Moss MB, Moore TL, Schettler SP, Killiany RJ, Rosene DL: Successful versus unsuccessful aging in the rhesus monkey; in Riddle DR (ed): Brain Aging: Models, Methods, and Mechanisms. Boca Raton, CRC Press, 2007, pp 21-38.
42 Herndon JG, Tigges J, Klumpp SA, Anderson DC: Brain weight does not decrease with age in adult rhesus monkeys. Neurobiol Aging 1998;19:267-272.

43 Hartmann P, Ramseier A, Gudat F, Mihatsch MJ, Polasek W: Das Normgewicht des Gehirns beim Erwachsenen in Abhängigkeit von Alter, Geschlecht, Körpergrösse und Gewicht. Pathologe 1994;15:165-170.

44 Rapp PR, Amaral DG: Evidence for task-dependent memory dysfunction in the aged monkey. J Neurosci 1989;9:3568-3576.

45 Riopelle AJ, Rogers CM: Age changes in chimpanzees; in Schrier AM, Stolnitz F (eds): Behavior of Nonhuman Primates: Modern Research Trends. New York, Academic Press, 1965, pp 449-462.
46 Judge DS, Carey JR: Postreproductive life predicted by primate patterns. J Gerontol A Biol Sci Med Sci 2000;55:B201-B209.

47 Jones KP, Walker LC, Anderson D, Lacreuse A, Robson SL, Hawkes K: Depletion of ovarian follicles with age in chimpanzees: similarities to humans. Biol Reprod 2007;77:247251.

48 Hawkes K, Smith K, Robson S: Mortality and fertility rates in humans and chimpanzees: how within-species variation complicates cross-species comparisons. Am J Hum Biol 2009;21:578-586.

49 Oeppen J, Vaupel JW: Demography. Broken limits to life expectancy. Science 2002;296: 1029-1031.

50 Database HM: University of California, Berkeley (USA), and Max Planck Institute for Demographic Research (Germany). Available at www.mortality.org or www. humanmortality.de (data downloaded on January 5, 2009). 